\title{
DIREITO À SAÚDE, ANIMAIS DOMÉSTICOS E O BEM-ESTAR DA FAMÍLIA MULTIESPÉCIE
}

\section{Tereza Rodrigues Vieira ${ }^{1}$}

\begin{abstract}
Alana Caroline Mossoi ${ }^{2}$
RESUMO: O artigo analisa, baseado em pesquisa bibliográfica e método dedutivo, a utilização ética de animais domesticados na prevenção, manutenção e recuperação da saúde da família. Com sentidos apurados, alguns animais atuam como acompanhantes de pessoas cegas, surdas, ou com surdo-mudez, e na prevenção de moléstias, como a depressão e, em algumas situações, ajudam a tratá-las, como no caso de crianças autistas. As famílias têm o dever de contribuir para a saúde e o bem-estar do animal. Conclui-se, portanto, que os animais de família são aliados na concretização do direito à saúde, pois auxiliam na prevenção e tratamento de doenças.
\end{abstract}

PALAVRAS-CHAVE: Animal; Bioética; Família Multiespécie; Saúde; Zooterapia

\section{RIGHT TO HEALTH, DOMESTIC ANIMALS AND THE WELL-BEING OF THE MULTISPECIES FAMILY}

\begin{abstract}
The article analyzes the ethical use of domestic animals in the prevention and recovery of family health. With keen senses, some animals act as companions for blind, deaf or deaf-mute people, and in the prevention of diseases, such as depression and, in some

\footnotetext{
${ }^{1}$ Pós-Doutora em Direito pela Université de Montreal, Canadá. Mestre e Doutora em Direito pela PUC-SP. Especialista em Bioética pela Faculdade de Medicina da USP. Docente e Pesquisadora do Mestrado em Direito Processual e Cidadania e da graduação em Medicina e Direito, na UNIPAR - Universidade Paranaense. Membro da Law and Society Association (USA). Membro da Sociedade Brasileira de Bioética. Advogada em São Paulo. terezavieira@ uol.com.br. Orcid 0000.0003.0333.7074 - http://lattes.cnpq.br/1171420054286283 Av.Paulista 2239/152, Bairro Jardins, São Paulo-SP, CEP 01311-300.

2 Mestranda em Direito Processual Civil na Universidade Paranaense (UNIPAR). Pós-Graduada em Direito Penal e Processo Penal na Universidade Paranaense (UNIPAR). Assessora de Magistrado no Tribunal de Justiça do Estado do Paraná. E-mail: alana_mossoi@ hotmail.com. Orcid https://orcid.org/0000-0002-8029-2992 http://lattes.cnpq.br/6954582852439718. Rua Paraná, nº 385, apto. 31, Jardim Porto Alegre, Toledo - PR, CEP 85906-120.
}

Revista de Biodireito e Direito dos Animais | e-ISSN: 2525-9695 | Encontro Virtual | v. 6 | n. 2 | p. 56 - 78 | Jul/Dez. 2020. 
situations, they help treating them, as in the case of autistic children. The families must contribute to animal health. The bibliographic review based on the deductive method was used. It is concluded that family animals are allies in the realization of the right to health, because they might help in the prevention and treatment of diseases.

KEYWORDS: Animal; Bioethics; Health; Multispecies Family; Zootherapy

\section{1 - INTRODUÇÃO:}

O objetivo geral do presente artigo é refletir, por meio da pesquisa bibliográfica e do método teórico, sobre a importância dos animais de família na prevenção, manutenção e tratamento de doenças, sem forçá-los ao trabalho, fato eticamente abominado.

Justifica-se, teoricamente, o estudo, na medida em que se atribui o não acometimento de algumas doenças pela população, como a depressão, por exemplo, em decorrência da presença de algum animal de estimação na família. Ademais, cavalos e cachorros, por exemplo, são utilizados como coadjuvantes terapêuticos, contribuindo para a saúde e o bemestar dos integrantes da família, conforme veremos.

O direito à saúde está contemplado no ordenamento jurídico, por intermédio do artigo 196 da Constituição Federal de 1988, o qual protege o direito ao bem-estar físico, mental, psicológico e social.

A interação entre seres de diferentes espécies, que configura a chamada família multiespécie, tem recebido alguma proteção jurídica, reforçando o vínculo desse agrupamento familiar, sujeito à tutela do Direito das Famílias. As omissões legislativas têm se curvado à análise jurisprudencial e doutrinária devido à importância social dos animais de estimação, sobretudo na seara psicológica e emocional da família.

Em agosto de 2019, o plenário do Senado aprovou o projeto de lei $\mathrm{n}^{\circ} 27 / 2018$, que criou o regime jurídico especial para os animais. Segundo o texto, os animais não humanos possuem natureza jurídica sui generis e são sujeitos de direitos despersonificados, os quais devem gozar e obter tutela jurisdicional em caso de violação, vedado o seu tratamento como coisa.

Revista de Biodireito e Direito dos Animais | e-ISSN: 2525-9695 | Encontro Virtual | v. 6 | n. 2 | p. 56 - 78 | Jul/Dez. 2020. 
Assim, os animais não poderão mais ser considerados objetos e serão sujeitos de direito despersonificados e, acima de tudo, serão reconhecidos como seres sencientes, ou seja, seres passíveis de sentir dor ou sofrimento emocional.

Destarte, pretende-se demonstrar a importância da interação do animal de companhia na família, reconhecendo a influência mútua da sua presença para o bem-estar biopsíquicosocial da família multiespécie.

\section{Direito à saúde da família multiespécie:}

As Constituições brasileiras, historicamente, não davam o devido valor à saúde. Segundo Maia (2012), o direito à saúde foi mencionado, acidentalmente, na Constituição de 1934, representando apenas mais uma competência administrativa da União, com o fim de promover o combate de endemias e epidemias.

Não obstante, a relação entre direito e saúde ganhou relevância a partir de 1988, e a sua cristalização foi fruto de amplos debates com grupos de pressão, sociedade civil e Estado (ASENSI, 2016).

Assim, a Constituição Cidadã de 1988, ao contrário das anteriores, reservou um lugar especial ao direto à saúde e o positivou como direito fundamental social, incluindo-o no catálogo dos Direitos Fundamentais, no artigo $6^{\circ 3}$, Título II - Dos Direitos e Garantias Fundamentais e no Título VIII - Da ordem social - Seção II, Da Saúde, nos artigos $196^{4}$ ao 200.

No artigo 196, a Constituição estabelece que a saúde é um "direito de todos e dever do Estado", o que evidencia a pretensão universalizante desse direito. Em decorrência disso, a saúde passa a ser caracterizada como um direito fundamental e dever do Estado (ASENSI,

\footnotetext{
${ }^{3}$ Art. $6^{\circ}$ São direitos sociais a educação, a saúde, a alimentação, o trabalho, a moradia, o transporte, o lazer, a segurança, a previdência social, a proteção à maternidade e à infância, a assistência aos desamparados, na forma desta Constituição.

${ }^{4}$ Art. 196. A saúde é direito de todos e dever do Estado, garantido mediante políticas sociais e econômicas que visem à redução do risco de doença e de outros agravos e ao acesso universal e igualitário às ações e serviços para sua promoção, proteção e recuperação.
}

Revista de Biodireito e Direito dos Animais | e-ISSN: 2525-9695 | Encontro Virtual | v. 6 | n. 2 | p. 56 - 78 | Jul/Dez. 2020. 
2016). Dessa forma, tem-se que o principal destinatário dos deveres fundamentais é, certamente, o Estado, na medida em que necessita efetivá-los.

Conquanto, isso não afasta uma eficácia no âmbito privado, sobretudo em termos de obrigações derivadas, ou seja, a noção de deveres fundamentais conecta-se ao princípio da solidariedade, no sentido de que toda a sociedade é também responsável pela efetivação e proteção do direito à saúde de todos e de cada um, no âmbito daquilo que o jurista português Canotilho denomina de uma responsabilidade compartilhada (shared responsability) (SARLET; FIGUEIREDO, 2008).

No prisma internacional, igualmente relevante, no preâmbulo da Constituição da Organização Mundial da Saúde, houve o reconhecimento expresso na sua base principiológica de que a saúde constitui um direito fundamental de todos os seres humanos, sem qualquer distinção (GUTIER; CORREIA JUNIOR; VENTURA, 2015).

Importante ressaltar que, segundo Sarlet e Figueiredo (2008), mesmo vigente o princípio da universalidade, no sentido de que o direito à saúde é reconhecido a todos pelo fato de serem pessoas, não há impedimento na diferenciação na aplicação prática da norma, especialmente quando sopesada com o princípio da igualdade, razão pela qual, embora correlacionados, tais princípios não se confundem.

Portanto, cabe ao Estado a realização de medidas voltadas à proteção da saúde das pessoas, efetivando o direito em sua dimensão negativa (no sentido de nãointerferência na saúde dos indivíduos) e positiva (organizando instituições e procedimentos direcionados à tutela individual e coletiva da saúde, tomando providências para o atendimento dos deveres de proteção, e fornecendo diretamente os bens materiais necessários à prestação da assistência à saúde) (SARLET; FIGUEIREDO, 2008), bem como a própria sociedade.

Não obstante, o modo de como se entende saúde e doença, há pouco tempo vem sofrendo alterações importantes e promovendo, consequentemente, mudanças nas políticas públicas de saúde (CRUZ, 2014). 
Mas qual o conceito de saúde? Segundo a Constituição de 1946, da Organização Mundial de Saúde - OMS, a saúde é entendida como um "completo estado de bem-estar físico, mental e social", ou seja, conceito biopsicossocial.

Dessa forma, entende-se como saúde tudo o que infere no bem-estar das pessoas, seja o bem-estar físico (aparência), mental ou social, ou seja, no meio em que estão inseridos.

Maia (2012) afirma a existência de críticas sobre o conceito em decorrência do uso das expressões "completo" e "bem-estar", cujas definições podem ser tormentosas na prática, pois a amplitude do conceito de saúde, em verdade, é proposital e tem por escopo salvaguardar, da melhor maneira, a saúde e a dignidade da vida humana.

Assim, para a Constituição, o direito à saúde é direito fundamental social, de $2^{\mathrm{a}}$ geração (ou dimensão), devendo ser protegido da maneira mais ampla possível, em virtude do dever de resguardo da dignidade humana (MAIA, 2012).

A fundamentalidade do direito social à saúde pode ser explicada por duas frentes: (a) formal e (b) material. A primeira se justifica pela previsão expressa no texto constitucional do rol dos direitos sociais $\left(\operatorname{art.} 6^{\circ}\right.$ ), e no capítulo atinente à seguridade social, no qual reconhece o texto constitucional a saúde como direito que anseia pela consagração de segurança social a todos, indistintamente, fixando ao poder público o dever geral de proteção (art. 196) (GUTIER; CORREIA JUNIOR; VENTURA, 2015).

Já o caráter fundamental, na acepção material, é retratado pela sua correlação essencial para a conservação digna da vida humana, de modo que é condição fundamental para usufruir dos demais direitos, sejam fundamentais ou não (GUTIER; CORREIA JUNIOR; VENTURA, 2015).

Desse modo, tem-se que o direito à saúde tem duas faces: uma é a da preservação da saúde; outra, a da proteção e recuperação da saúde. O direito à preservação da saúde tem, como contrapartida, as políticas que visam à redução do risco de doença, situando-se o próprio direito a um meio ambiente sadio, sendo uma prevenção genérica, não individualizável da doença (RAMOS, 2005). 
Já o direito à proteção e recuperação da saúde é o direito individual à prevenção da doença e seu tratamento traduz-se no acesso aos serviços e ações destinados à recuperação do doente. Enquanto o primeiro é típico direito de solidariedade, o segundo é típico direito fundamental à prestação positiva (RAMOS, 2005).

Assim, tem-se que os governos possuem responsabilidades pela saúde do seu povo, a qual pode ser assumida pelo estabelecimento de medidas sanitárias e socialmente efetivas, ou seja, o direito à saúde exige a interação entre o Estado e a sociedade, voltada ao desenvolvimento das condições que permitirão o acesso à saúde.

Não obstante, segundo Sarlet e Figueiredo (2008), em um estudo publicado pela Organização Mundial de Saúde (OMS), percebe-se a existência de diferenças radicais nas condições de saúde de pessoas pertencentes a diferentes grupos populacionais, inclusive dentro de um mesmo (e desenvolvido) país, fato que afasta a consideração de fatores meramente biológicos para destacar, como causa principal do problema, os denominados "determinantes sociais de saúde", ou seja, "o ambiente no qual as pessoas nascem, vivem, crescem, trabalham e envelhecem".

Posto isso, é de bom alvitre lembrar que não é novidade para ninguém que animais são usados em pesquisas objetivando a descoberta para a cura de doenças humanas. Contudo, o presente artigo não trata de pesquisa em animais, mas sim, em benefícios recíprocos, uma vez que pessoas e animais de estimação são acometidos por doenças e ambos fazem parte do reino animal.

Cabe às famílias cuidar da saúde dos animais, contribuindo na prevenção de doenças com vacinas e lhes concedendo morada em ambientes salubres, assim como, real interação com os humanos uma vez que, quando não há o tratamento adequado aos animais, há a possibilidade de que doenças neles presentes possam ser transmitidas aos seres humanos, como a raiva canina, por exemplo. Ressalte-se aqui que:

90\% dos casos de raiva são causados por mordidas de cães (há mais de 60.000 mortes por raiva anualmente em todo o mundo) e reduzimos os riscos vacinando animais. Para ter sucesso nesse tipo de operação, a colaboração da comunidade é essencial. (SAUVÉ, 2019).

Revista de Biodireito e Direito dos Animais | e-ISSN: 2525-9695 | Encontro Virtual | v. 6 | n. 2 | p. 56 - 78 | Jul/Dez. 2020. 
Pesquisadores como Michèle Bouchard, diretora do Departamento de Saúde Ambiental da Universidade de Montreal, defende a interdisciplinaridade. Segundo ela: “A saúde humana está ligada à dos animais. É necessária uma melhor colaboração entre as ciências da saúde e as ciências sociais para permitir a co-construção do conhecimento" (SAUVÉ, 2019).

A consideração moral indica que existe o dever de respeito pelo bem-estar dos animais e isso envolve recursos com tratamentos médico-veterinários, além de dedicação de tempo para cuidados e lazer. Há pessoas que, inclusive, mudam de planos para não haver a possibilidade de deixar o animal sozinho em casa.

Ademais, havendo ou não afeto entre os membros humanos da família e o pet, há o dever do cuidado, não podendo o animal ser abandonado, desnutrido ou sofrer maus tratos, pois abarca a responsabilidade do seu guardião ou da família toda. (VIEIRA; CARDIN, 2017, p. 131). O princípio da paternidade responsável, mutatis mutandis, pode ser aplicado como guarda responsável, conforme veremos a seguir.

Dessa forma, tem-se que a saúde é um direito de todos, nela incluída a prevenção e tratamento das doenças. Nessa esteira, há diversas formas de saúde em diferentes locais, com características especificas, de forma que se faz necessária a proteção de todas as formas que permitam a efetivação da saúde, como a proteção dos animais de estimação (animais de família), na medida em que são fortes aliados na prevenção e tratamento de doenças, segundo abaixo será demonstrado.

\section{A guarda responsável para efetivação da saúde do animal:}

A vulnerabilidade do animal doméstico passou a ser uma responsabilidade do homem, a partir do momento em que este o domesticou e alterou sua forma de vida.

Conforme se infere da realidade, a relação entre as pessoas e os animais de estimação está cada vez mais próxima e íntima. Isso é possível de se perceber a começar pelos novos termos utilizados, como, o nome atribuído às pessoas que têm um animal de estimação, 
anteriormente donos ou proprietários, agora são chamados de tutores ou guardiões (WITTER, 2016).

Os animais de estimação antes chamados bichos, agora são filhos; o ato de levar um animalzinho para casa agora é denominado de adoção, termo utilizado antes somente para seres humanos; antes chamada de posse, hoje guarda responsável (WITTER, 2016), em decorrência da tutela da doutrina e dos tribunais ao reconhecimento da família multiespécie.

Graças a eles, as pessoas não se sentem mais sozinhas, pois um cachorro, por exemplo, transmite segurança e estimula o contato físico e a comunicação. Aliás, no dizer de Cabral e Silva (2020, p. 175),

\footnotetext{
“oferecer uma específica tutela jurídica aos animais é proteger a própria ideia de senciência, é observar de forma coerente o sistema constitucional como um todo, que é regido pelos Princípios da Dignidade e da Afetividade, deixando de observar ideais de ordem moral, que são arcaicos e antropocêntricos que engessam o conceito de família."
}

Ter um animal de companhia gera um impacto positivo na vida da pessoa e do animal, portanto, essa guarda deve ser responsável. Esta, por sua vez, é um instituto do Direito Animal que objetiva preservar a saúde animal e impedir que certas práticas na relação entre o humano e os não humanos se configurem em crueldade, abandono e superpopulação de animais domésticos no meio ambiente urbano. Ademais, "a saúde de uma população de animais inclui a preservação desta população dos riscos de ser exposta ou afetada a doenças de notificação obrigatória" (SANTANA; OLIVEIRA, 2019, p. 31).

No entender de Maria Berenice Dias (2016, p. 233), “o novo modelo da família funda-se sobre os pilares da repersonalização, da afetividade, da pluralidade e do eudemonismo, impingindo nova roupagem axiológica ao direito das famílias". A guarda responsável implica na relação descoisificada entre homem e o animal de estimação, onde não há exploração, de maneira que o homem o trate como membro da família.

O conceito de família varia de conformidade com o tempo e o lugar. Hodiernamente, valoriza-se mais a afetividade, assim, o "escopo precípuo da família passa a ser a solidariedade social e demais condições necessárias ao aperfeiçoamento e progresso humano, regido o núcleo familiar pelo afeto, como mola propulsora" (FARIAS; ROSENVALD, 2017, p. 35). No dizer de Leandrini, "família pluriespécie é aquela que advém do afeto, da 
convivência, em que os laços que os unem não são os consanguíneos, mas os de carinho" (LEANDRINI, 2016, p. 23).

Assim, a família não tem sua base apenas na consanguinidade, mas também na adoção, inclusive, de animais de outras espécies. Porém, os animais domésticos dependem do cuidado do homem, devendo este prover-lhes alimento, higiene, afeto e cuidados com a saúde.

A relação entre homem e animal doméstico é dinâmica e benéfica para ambas as partes. Os animais são tratados como filhos, cercados de carinho, cuidados e atenção. No dizer de Leite et al., referida relação é "baseada na estima, na afetividade, no apreço, no amor, na ternura, na afeição, no carinho, na benquerença. É relação que envolve sentimento e que, por isso mesmo, exige um tratamento cuidadoso" (LEITE et al., 2015, p. 7). Lamenta o homem, frequentemente, a pouca longevidade do animal de estimação, contudo, graças ao progresso da medicina veterinária e dos cuidados da família, o prolongamento da vida da mascote tem aumentado.

A guarda responsável de animais deve ser exercida tanto pelo Estado, por meio de políticas públicas de educação para a tutela responsável e fiscalização dos deveres do guardião, quanto pelo particular e Estado juntos, na atenção à vacinação, à esterilização, ao controle do comércio de animais domésticos e na educação para a guarda responsável.

Já o conjunto de deveres (alimentar, abrigar, cuidar da saúde, não maltratar, oferecer afeto, etc.) que vinculam o guardião do animal não humano seria concebido como a dimensão imediata da guarda responsável dos animais, que vincularia tanto pessoas naturais, quanto pessoas jurídicas e, até mesmo, entes despersonalizados, a depender do caso concreto.

De acordo com a ANSES, Agence Nationale de Sécurité Sanitaire de l'Alimentation, de l'Environnement et du Travail, da França, o bem-estar de um animal é o estado físico e mental positivo associado à satisfação de suas necessidades fisiológicas e comportamentais, bem como suas expectativas. Este estado varia em função da percepção da situação do animal. (RYAN et al, 2020, p. 4). 
Todas as recomendações e protocolos devem ser avaliados para garantir que eles tragam melhor bem-estar para todos os animais em tratamento em locais especializados. As clínicas veterinárias e suas equipes precisarão proteger o bem-estar não apenas de seus pacientes e proprietários, mas também da comunidade, geralmente, promovendo e propondo conhecimento profissional, gerenciando populações urbanas de cães e gatos para limitar a quantidade de animais abandonados e fornecendo exercícios físicos e intelectuais para cães (e seus donos) em todos os ambientes. (RYAN et al, 2020, p. 4).

O animal de estimação tem interação cotidiana direta com os guardiões, responsáveis pelos cuidados, os quais não devem ser subestimados. O homem tem o dever de solidariedade e manifestação de igual consideração entre os interesses.

\section{Animais de família como seres sencientes e a zooterapia:}

Com o passar dos anos, o homem passou a domesticar determinados animais e eles passaram a ser companheiros de jornada e a influenciar, diretamente, na saúde psíquica e, até mesmo, corporal dos seres humanos, passando à denominação de animais de estimação.

Para Wisniewski (2019), os animais de estimação, também chamados de animais de companhia ou, ainda, animais domésticos, são aqueles que permanecem no lar, tais como: cães, gatos, hamsters, peixes de aquário, coelhos, iguanas, furões etc., desde que não abarcados pela legislação especial que impeça sua detenção. (VIEIRA; MOSSOI, 2020).

Segundo uma pesquisa realizada pelo Instituto Brasileiro de Geografia e Estatística IBGE, o Brasil é o $4^{\circ}$ país com a maior população de animais de estimação do mundo. Em 2013, a pesquisa estimou que 44,3\% dos domicílios do país possuíam, pelo menos, um cachorro, o equivalente a 28,9 milhões de unidades domiciliares. A Região Sul apresentou a maior proporção $(58,6 \%)$ e a Região Nordeste, a menor $(36,4 \%)$. Na área rural, a proporção de domicílios com algum cachorro (65,0\%) era superior à observada na área urbana (41,0\%). A população de cachorros em domicílios brasileiros foi estimada em 52,2 milhões, o que indicou uma média de 1,8 cachorro por domicílio com esse animal. 
Outra pesquisa realizada pelo, anteriormente, citado, Instituto Brasileiro de Geografia e Estatística (IBGE), verificou que as casas brasileiras contam com 52 milhões de cães, enquanto que o número relacionado às crianças seria de 45 milhões.

Percebe-se, facilmente, que, em muitos casos, a sociedade/casais está transferindo o papel dos filhos para os animais e, por esta razão, despendem um zelo e cuidado com os animais, sem distinção ou discriminação sobre qualquer espécie.

Os benefícios da relação humana com os animais da família são incontestáveis e já foram comprovados cientificamente na mudança do comportamento do ser humano, para melhor. Outrossim, é possível perceber que o comportamento do animal também é alterado de acordo com o ambiente em que ele vive (WITTER, 2016).

Todas as atitudes dos animais, por muito tempo, foram explicadas pelo instinto. Segundo Witter (2016), já foi provado cientificamente que uma boa parte dos animais é senciente, dotada de sensibilidade, ou seja, tem capacidade de sentir e não a mera capacidade de perceber um estímulo ou reagir a uma ação como uma máquina que desempenha funções.

A senciência dos animais é verificada em algumas situações práticas, como no caso de dor perpetrada pelo cavalo Sereno $^{5}$ (LIRA, 2018).

Não obstante a existência da sensibilidade dos animais, vários estudos mostram que os animais de estimação promovem mudanças positivas no comportamento das pessoas, estimulam o desenvolvimento de atividades e o exercício da responsabilidade.

Segundo alguns estudos, em decorrência do olfato apurado e da capacidade de captar frequências inaudíveis para o homem, os animais de estimação podem captar sentimentos, expectativas, intenções, alterações químicas do organismo humano, possibilitando identificar o humor, a saúde e o estado geral (CARRÃO, 2017).

\footnotetext{
${ }^{5}$ Wagner Figueiredo de Lima, tutor de Sereno, faleceu em um acidente de carro. Ambos eram inseparáveis. No dia do velório, o irmão de Wagner levou o animal de estimação para se despedir do falecido. Quando o carro que levava o corpo de Wagner chegou, Sereno se aproximou dele, como se realmente soubesse que era o último adeus a seu amigo humano. Nesse momento, Sereno começou a cheirar, circundar o veículo, relinchar e encostar a face sobre o caixão. (LIRA, 2018).
} 
Conforme relatam Albuquerque e Ciari (2016), os cães e seres humanos possuem sistemas comunicativos semelhantes, pois ambos enfatizam os sinais visuais do corpo e do rosto. Se comparado ao lobo cinza, ancestral mais próximo, verificar-se-á que o repertório comportamental dos cães domésticos perdeu diversas características. Em contrapartida, segundo as autoras retrocitadas, surgiram novos comportamentos advindos de milhares de anos de convivência com os seres humanos, resultando em ampla sensibilidade a pistas gestuais e comunicativas das pessoas.

E continuam Albuquerque e Ciari (2016, p. 16):

Durante os últimos milhares de anos, os ambientes sociais dos filhotes de cães e crianças foram se tornando cada vez mais semelhantes e uma consequência dessa intensa coabitação é a habilidade dos cães de exibirem alguns comportamentos vistos por muito tempo como unicamente humanos, como o reconhecimento do estado de atenção, a compreensão de gestos comunicativos e a discriminação de emoções.

Em estudo protagonizado por Morizaki et al, em 2009, verificou-se a capacidade de percepção de emoções em cães. Referidos cientistas estudaram o comportamento de cães domésticos durante interação com seus tutores. Para chegarem ao resultado, eles:

Filmaram cães enquanto observavam seu tutor a assistir duas categorias de vídeo: que elicitava emoções positivas (alegria) e que elicitava emoções negativas (tristeza). Os resultados mostraram que os cães olharam por um período maior de tempo quando seu tutor assistia ao filme alegre. Os autores argumentaram que essa é uma evidência de que os cães são sensíveis às emoções dos seres humanos (WITTER, 2016, p. 13).

Carrão (2017) afirma que há pesquisas no sentido de que boa parte das pessoas que convivem com animais domésticos vão menos ao médico e a grande maioria diz que confessa coisas aos seus animais que não falariam a mais ninguém. Além disso, ainda afirma que eles melhoram a saúde física, psicológica e emocional do homem, diminuem tensões entre membros da família, reduzem o tempo de recuperação das doenças, ajudam na maior sobrevida das pessoas, reduzem o sentimento de solidão, reduzem a pressão sanguínea, aumentam o cuidado pessoal e autoestima, expandem o número de células de defesa do organismo e reduzem os sintomas da depressão.

Em decorrência dessa sensibilidade dos animais em captarem sinais, em especial os de família, foi desenvolvida a terapia assistida por animais que é uma prática na qual o animal 
é a parte principal do tratamento, objetivando promover a melhora social, emocional, física e, até mesmo, cognitiva de pacientes humanos (MACHADO, 2008).

A descoberta desta terapia ocorreu em 1953, no consultório de Boris Levinson, um psiquiatra, quando percebeu que, com a presença do seu cão no consultório, os pacientes introvertidos perdiam todas as suas inibições e medos, o que favorecia a comunicação entre o psiquiatra e os pacientes (GALENO, 2019).

Segundo Galeno (2019), esse tipo de terapia apresenta uma série de variações e pode ser conhecida por diferentes nomenclaturas, tais como: terapia assistida por animais (TAA); terapia facilitada por animais, pet-terapia, cinoterapia (quando utiliza cães), equoterapia (quando utiliza cavalos); atividade assistida por animais (quando tem um direcionamento e um objetivo diferente da terapia).

A terapia parte do princípio de que o amor e a amizade que podem surgir entre seres humanos e animais geram inúmeros benefícios, razão pela qual o animal é um catalisador, pois age de forma não interventiva, existindo apenas a interação com o animal e a pessoa, simplesmente, reagirá com afeto, com vontade de brincar (GALENO, 2019).

Neste sentido, também, é o entendimento de Ramos e Dylewski (2016, 289-290), as quais ressaltam que os benefícios da Terapia Assistida por Animais aumenta o estímulo para a prática de exercícios físicos, favorece as condições psíquicas, sociais, emocionais e cognitivas dos pacientes e estimula o desenvolvimento psicomotor e sensorial, objetivando melhorar "a capacidade de socialização e recuperação da autoestima, podendo auxiliar na qualidade das interações psicológicas e físicas entre pessoas, animais e ambiente, por meio do estímulo a exercícios físicos e do efeito emocionalmente positivo produzido com a atividade”. Assim, reiteram as pesquisadoras retrocitadas os benefícios observados:

Sensação de bem-estar, diminuição do estado de dor, encorajamento das funções motoras e da fala, mudanças na rotina, redução da tendência ao isolamento, estímulo de troca de informações com outras pessoas, aumento da sensação de segurança, motivação e troca de afeto (RAMOS; DYLEWSKI, 2016, p. 290).

Dessa forma, se os animais de família são sencientes e podem captar alterações químicas do organismo dos seus amigos humanos, podem ajudar na prevenção e no 
tratamento de doenças, sendo que os cães ocupam o maior espaço neste tratamento, juntamente com os cavalos, conforme veremos no próximo tópico.

\section{A importância dos animais de estimação na prevenção e no tratamento de doenças na família:}

A importância dos animais, em especial aqueles que convivem diariamente com as pessoas, já foi comprovada reiteradas vezes. Em 2000, por exemplo, foi fundada a Organização Brasileira de Interação Homem-Animal Cão Coração, que promove o Projeto Cão do Idoso. Tal atividade é aplicada em casas de repouso ou abrigos com a finalidade de melhorar a qualidade de vida, o bem-estar, integridade e respeito ao idoso (KOBAYASHI, 2009).

Outro caso de utilização de animais foi verificado em Araçatuba-SP. A Faculdade de Medicina Veterinária, em parceria com a Faculdade de Odontologia, da Universidade Estadual de São Paulo, campus Araçatuba, iniciou, em 2003, o projeto “Cão-CidadãoUnesp”, que investiga as reações que os animais provocam em crianças com necessidades especiais, como as que sofreram paralisia cerebral, as portadoras de Síndrome de Down e de outros tipos de comprometimento mental (MACHADO, 2008).

A relevância dos cães na vida de uma criança também pode ser verificada no projeto conduzido pela Faculdade Médica Veterinária e Zootecnia da Universidade de São Paulo, campus Pirassununga. Com o projeto "Dr. Escargot", os pesquisadores buscam demonstrar que a existência de um cão, inclusive em ambientes escolares e hospitalares, proporciona aprimoramento ético, moral, cidadania e qualidade de vida às crianças e idosos. Segundo o projeto, o cão prende a atenção dos jovens, obrigando as crianças hiperativas a fixarem o olhar no animal (GALENO, 2019).

Consoante Priscila Gorzoni (2010), os pacientes com HIV também se beneficiam com a companhia de animais, pois segundo um estudo desenvolvido pela psicóloga americana Judith Siegel, da Universidade da Califórnia, campus Los Angeles, os casos de depressão entre os infectados foram duas vezes mais numerosos nos que viviam sós do que naqueles que conviviam com animais de estimação.

Revista de Biodireito e Direito dos Animais | e-ISSN: 2525-9695 | Encontro Virtual | v. 6 | n. 2 | p. 56 - 78 | Jul/Dez. 2020. 
Com o intuito de aumentar a qualidade de vida, surgiram os trabalhos com cães de assistência. Bastante conhecidos são os cães-guias, uma vez que foram os primeiros animais a receberem treinamento para auxiliar deficientes visuais, sobretudo na Europa, no período pósPrimeira Guerra Mundial, em decorrência do alto número de pessoas feridas.

Depois, surgiu o treinamento para cães de assistência a "deficientes auditivos, portadores de síndromes incapacitantes, pessoas sujeitas a convulsões e a paradas respiratórias súbitas" (ALBUQUERQUE; CIARI, 2016, p. 18). Outrossim, conforme citamos alhures, cães foram descobertos como auxiliares em tratamentos psicológicos.

Não obstante o tratamento psicológico, os cães estimulam a criança com deficiência a "se abrir para os outros e ter confiança em si mesmas. As crianças conseguem executar movimentos que jamais pensaram poder atingir. A ajuda trazida pelo cão as impulsiona a ultrapassar seus limites", como nos casos de autismo, por exemplo (ENCICLOPÉDIA DO CÃO ROYAL CANIN, 2001, p. 156-157).

O Transtorno do Espectro do Autismo (TEA) é um problema grave e precoce do desenvolvimento que ocorre antes dos três anos de idade. Caracteriza-se pelo isolamento, interrupção das interações sociais, comprometimento da linguagem, comunicação não verbal e atividades estereotipadas com interesses restritos. Não é uma doença mental, mas consta na Classificação Estatística Internacional de Doenças e Problemas Relacionados à Saúde, CID11, sob o código 6A02. Pessoas com autismo têm problemas com a comunicação, apresentando dificuldade para entender o que as outras pessoas pensam e sentem, dependendo do grau em que é tocada pelo transtorno. Este dificulta a expressividade por meio de palavras ou por meio de gestos, expressões faciais e toques. Os sintomas mais comuns do autismo incluem: falta de contato visual, fazer algo repetidamente, como reproduzir palavras ou frases, balançar para frente e para trás, alta sensibilidade a sons, toques, cheiros ou imagens que parecem comuns a outras pessoas, não olham as coisas quando outra pessoa aponta para elas, não querem ser abraçadas, têm problemas para entender ou usar fala, gestos, expressões faciais ou tom de voz, etc (BANDHARI, 2019). 
Ao considerarmos que um dos grandes problemas enfrentados pelo autista é a falta de interação e manter relacionamentos, "os animais podem atuar como um catalisador inicial para suportar interações sociais e parecem deixar as pessoas mais confortáveis dentro do ambiente terapêutico" (MUÑOZ; ROMA, 2016, p. 278).

Portanto, as crianças portadoras de autismo, quando possuem como companhias um cão, apresentam significativa melhora no seu quadro, pois a utilização de animais na terapia com pessoas autistas facilita a interação ao estimular o desenvolvimento de habilidades, pois assim como os animais, o autista percebe o mundo em termos sensoriais. Ademais, com o animal certo e um ambiente de terapia adequado, a presença do animal na família pode oferecer um novo foco de atenção, possibilitando a modulação da ansiedade e a abertura da possibilidade de vinculação entre paciente e terapeuta (MUÑOZ; ROMA, 2016, p. 286).

Desta forma, as crianças autistas que possuem animais de estimação apresentam diminuição nos comportamentos negativos, como agressividade, alienação e isolamento, por exemplo.

Na mesma esteira da importância dos cachorros no desenvolvimento e tratamento de crianças com doenças, temos os cavalos. A equoterapia, uma modalidade da TAA, teve seus primeiros relatos como tratamento médico no século XVIII, com o objetivo de melhorar o controle postural, a coordenação e o equilíbrio de pacientes com distúrbios articulares (KOBAYASHI, 2009).

Ao estar sobre o animal, há similaridade entre o ritmo do movimento do animal e do ser humano de forma que permite, durante a cavalgada, o fortalecimento da musculatura de pessoas com habilidade limitada de funções motoras, comuns em casos de paralisia cerebral, esclerose múltipla, espinha bífida e traumatismos cerebrais (MACHADO, 2008).

A título de exemplo da importância dos animais no tratamento de doenças, a cidade de Toledo-PR, é uma das poucas cidades que oferta, há mais de uma década, o tratamento de equoterapia, pelo Sistema Único de Saúde (SUS), em convênio com o Consórcio Intermunicipal de Saúde Costa Oeste do Paraná (Ciscopar) e colhem resultados positivos na reabilitação de pacientes com todos os tipos de síndromes, transtornos e deficiências (VIEIRA; MOSSOI, 2020). 
Os problemas vivenciados no acesso aos serviços de saúde são mais evidentes na assistência farmacêutica, mais especificamente em relação ao acesso da população aos medicamentos essenciais para doenças como de Crohn, hepatite viral crônica C, doença renal em estágio final, hipertensão arterial e doença isquêmica crônica do coração (GUTIER; CORREIA JUNIOR; VENTURA, 2015).

Nessa esteira, tem-se que as doenças cardíacas, um dos principais problemas de saúde pública, podem ser resolvidas pelo simples fato de existirem animais na família. Segundo a UNIMED (2015), em uma pesquisa realizada pela Baker Medical Research Institute comprovou-se que proprietários de cães e gatos apresentam taxas menores de colesterol e triglicérides que aqueles que não tinham animais. Ambas as taxas, se mantidas altas, favorecem a aterosclerose, formação de placas que entopem as artérias, possibilitando infartos e outros problemas no coração.

Diante do acima exposto, tem-se que os animais de estimação trazem inúmeros benefícios para o ser humano, tornando-se uma oportunidade excelente para o progresso da ciência, proporcionando mais pesquisas que visam apreender o potencial, ainda não imaginado ou percebido nesta relação e, espaços terapêuticos possíveis (GALENO, 2019).

Logo, há um benefício significativo e uma melhora na saúde das pessoas que convivem com animais de estimação, na medida em que são estimuladas a serem pessoas melhores, que se preocupam com as outras e, em troca, recebem estímulos dos animais, que ajudam a prevenir e, até mesmo, tratar doenças que já foram diagnosticadas.

Percebe-se ainda, que a utilização de animais no tratamento de algumas doenças pode ser uma saída para o Estado, na medida em que os gastos com os animais podem ser menores do que com os próprios medicamentos. Uma sugestão viável seria o fornecimento de animais (como cães de rua, após prévia habilitação/triagem) para famílias carentes e que são acometidas por doenças. Talvez seja uma saída viável, oferecendo, inclusive, um lar para os animais abandonados nas ruas (VIEIRA, 2020), uma vez que estes também merecem, por si só, atenção e respeito.

\section{CONSIDERAÇÕES FINAIS:}


Os animais de companhia são grandes aliados na prevenção e tratamento de doenças, uma vez que compartilham afeto na família. Os animais são seres sencientes, razão pela qual possuem sentimentos, em especial de dor e tristeza. Nesse ínterim, de senciência, há inúmeros projetos que visam alterar o Código Civil. O projeto de lei $\mathrm{n}^{\mathrm{o}} 27 / 2018$, que foi aprovado em agosto de 2019, criou o regime jurídico especial para os animais, passando estes a terem a natureza jurídica sui generis e sujeitos de direitos despersonificados, não podendo ser tratados como coisas.

No mesmo sentido, de importância dos animais, foi verificado em pesquisas, que pessoas que possuem animais na família apresentam benefícios no tocante a inexistência ou cura de moléstias, quando comparada com aquelas que não possuem pets na família.

Os estudos da utilização dos animais avançaram e foi desenvolvida a zooterapia. É por intermédio dela, que muitas pessoas tratam inúmeras doenças, como autismo ou paralisias. Esta modalidade de tratamento é baseada na presença de um animal, que contribui para que a pessoa seja estimulada a novos comportamentos, como um cachorro para crianças autistas, na qual se instiga a interação com outras pessoas por intermédio do animal de estimação. Ou ainda, utilizar o animal de família para prender a atenção de crianças hiperativas.

Mais importante do que tratar, os animais de família ajudam a prevenir doenças. Por intermédio dos sentidos apurados, podem captar alterações químicas nos humanos e permitir a descoberta de doenças que estão no início, como, a depressão.

Como vimos, dentre outros, são diversos os benefícios constatados pelos estudos acerca do tema, os quais estimulam o aumento de exercícios físicos das pessoas, melhoram as condições gerais da saúde cardiovascular; promovem a sociabilidade e os efeitos antiestresse. Os animais não humanos são importantes na assistência e no desenvolvimento de diversas terapias educacionais e motivacionais, contribuindo para o bem-estar das pessoas, com ou sem deficiências e síndromes.

Destarte, são extremamente perceptíveis as benesses que um animal de família pode trazer para as pessoas que convivem ao seu redor, indo muito além de auxiliar em moléstias, mas, em especial, na tradução do sentimento de amor transmitido. 
Importante ressaltar que os animais participantes da terapia assistida devem apresentar condições físicas e sociais para integrarem um programa de reabilitação. $\mathrm{O}$ acompanhamento de um médico veterinário é imprescindível, assegurando o bem-estar sanitário. Sem isso, a terapia não funcionará.

É imprescindível investir mais em pesquisas para o entendimento das habilidades cognitivas dos animais e estudar os importantes mecanismos de interação homem animal. Contudo, é fundamental uma atitude ética em relação ao animal, uma vez que lhe é devido o respeito e igual consideração.

\section{REFERÊNCIAS DAS FONTES CITADAS:}

ALBUQUERQUE, N. S.; CIARI, M. B. Cães e seres humanos: uma relação forte, complexa, duradoura e vantajosa. In_Terapia assistida por animais. Coordenadoras Marie Odile Monier Chelini e Emma Otta. Barueri, SP: Manole, 2016.

ASENSI, F. D. Judicialização da saúde e Conselho Nacional de Justiça: Perspectivas e desafios. Fórum Administrativo - FA, Belo Horizonte, ano 16, n. 186, ago. 2016. Disponível em: <http://www.bidforum.com.br/PDI0006.aspx?pdiCntd=243174>. Acesso em: 27 jan. 2020.

BANDHARI, Smitha. WebMD. Autism. Disponível em: https://www.webmd.com/brain/autism/understanding-autism-basics. Edição de 22 Out. 2019. Acesso em: 25 mar. 2020.

CABRAL, L. M. S.; SILVA, T.T.A. O não humano no agrupamento familiar: novo conceito de guarda compartilhada na família multiespécie. In_Família Multiespécie: Animais de estimação e direito. Tereza Rodrigues Vieira e Camilo Henrique Silva organizadores. Brasília: Zakarewicz, 2020.

CARRÃO, M. S. A. Família multiespécie: a guarda de animais de estimação nos casos de dissolução litigiosa da sociedade e vínculo conjugal. Disponível em: < https://repositorio.uniceub.br/jspui/bitstream/235/11273/1/21272010.pdf>. Acesso em: 29 jan. 2020.

Revista de Biodireito e Direito dos Animais | e-ISSN: 2525-9695 | Encontro Virtual | v. 6 | n. 2 | p. 56 - 78 | Jul/Dez. 2020. 
CRUZ, J. S. Direito à saúde, experimentação animal e controversas ilusões. Revista Brasileira de Direito Animal. Bahia, vol. 9, 2014.

DIAS, M. B. Manual de Direito das Famílias: de acordo com o novo CPC. 11. ed. São Paulo: Revista dos Tribunais - Thomson Reuters, 2016.

Enciclopédia do Cão Royal Canin, Volume 1. Tradução: S. Artamonoff, B. Delevallee, M. D’Orey de Faria, L. Gonçalves, B. Magne, E. Rio Branco, M. Rosenberg, Mme Antunes. Edição Brasileira: 2001, p.156-157.

FARIAS, C. C.; ROSENVALD, N. Curso de direito civil: famílias. 9. ed. Salvador: JusPodivm, 2017.

GALENO, L. F. Terapia assistida com animais: cães promovendo saúde e felicidade. Disponível em:

https://www.researchgate.net/publication/334945776_TERAPIA_ASSISTIDA_COM _ANIMAIS_CAES_PROMOVENDO_SAUDE_E_FELICIDADE > Acesso em: 30 jan. 2020.

GORZONI, P. Dona de casa do Século XXI. São Paulo: Universo dos livros, 2010. Disponível em:

https://books.google.com.br/books?id=dg84rueSfLwC\&pg=PT59\&lpg=PT59\&dq=os + pacientes+com+HIV+tamb\%C3\%A9m+se+beneficiam+com+a+companhia+de+ani mais\&source $=$ bl\&ots $=$ Yw2giO6jk\&sig=ACfU3U3x6QQmqID_NbS4Ev8fwTeEHrxUw\&hl=pt-

BR\&sa=X\&ved=2ahUKEwjWhYDg63pAhUJJrkGHb16DA8Q6AEwBXoECAwQAQ\#v=onepage\&q=hiv\&f=false. Acesso em: 6 jun. 2020 .

GUTIER, M. S.; CORREIA JUNIOR, R.; VENTURA, C. A. A. O direito fundamental à saúde e a judicialização no Brasil: A saúde como direito humano e sua tutela processual. Revista Brasileira de Direito Processual - RBDPro, Belo Horizonte, ano 23, n. 89, jan./mar. $2015 . \quad$ Disponível em: <http://www.bidforum.com.br/PDI0006.aspx?pdiCntd=232309>. Acesso em: 27 jan. 2020.

Revista de Biodireito e Direito dos Animais | e-ISSN: 2525-9695 | Encontro Virtual | v. 6 | n. 2 | p. 56 - 78 | Jul/Dez. 2020. 
KOBAYASHI. C. T. et.al. Desenvolvimento e implantação de Terapia Assistida por Animais em hospital universitário. Revista Brasileira de Enfermagem - REBEN. Brasília, jul. - ago. 2009.

LEANDRINI, C. S. Do bem estar dos animais domésticos: o reconhecimento da família pluriespécie e a guarda. Biodireito e direitos dos animais II - CONPEDI, UNICURITIBA. GORDILHO, H. J.; ALKIMIN, M. A. (Coord.), Florianópolis: CONPEDI, 2016.

LEITE, M. F. L. et al. O Rompimento de Relações Pessoais e o destino do animal de estimação: divisão de bens ou guarda? Universidade Tiradentes. Curso de Graduação em Direito Trabalho de Conclusão de Curso - Artigo Científico. Aracaju, 2015.

LIRA, A. Cavalo que se despediu de vaqueiro morto na PB mudou comportamento, diz irmão. G1 PB. Publicado em 05/01/2018. Disponível em: https://g1.globo.com/pb/paraiba/noticia/cavalo-que-se-despediu-de-vaqueiro-mortona-pb-eda-familia-diz-irmao-de-vitima.ghtml. Acesso em: 10 set. 2020.

MACHADO, J. A. C., et. Al. Terapia assistida por animais (TAA). Revista Científica Eletrônica de Medicina Veterinária. São Paulo, ano VI, Número 10, jan. 2008.

MAIA, M. C. O direito à saúde à luz da constituição e do código de defesa do consumidor. Revista dos Tribunais. São Paulo, vol. 84, dez. 2012.

MUÑOZ, P. O. L.; ROMA, R. P. S. Terapia assistida por animais e autismo. In_Terapia assistida por animais/ coordenadoras Marie Odile Monier Chelini, Emma Otta. Barueri, SP: Manole, 2016.

RAMOS, C. M.. DYLEWSKI, Viviana. Reabilitação e terapia assistida por animais. In_ Terapia assistida por animais/ coordenadoras Marie Odile Monier Chelini, Emma Otta. Barueri, SP: Manole, 2016, p. 289-290.

RAMOS, M. C. S. O direito fundamental à saúde na perspectiva da Constituição Federal. A\&C Revista de Direito Administrativo e Constitucional, Belo Horizonte, ano 5, n. 22, p. 147-165, out./dez. $2005 . \quad$ Disponível em: <http://www.bidforum.com.br/PDI0006.aspx?pdiCntd=33319>. Acesso em: 27 jan. 2020. 
RYAN, Shane; BACON, Heather; ENDENBURG, Nienke Endenburg; HAZEL, Susan; JOUPPI, Rod ; LEE, Natasha; SEKSEL, Kersti; TAKASHIMA, Gregg. Guide du bien-être animal. Traduction offerte par la Fédération des associations francophones de vétérinaires d'animaux de compagnie. 2020.

SANTANA, L. R.; OLIVEIRA, T. P. Direito da saúde animal. Curitiba: Juruá, 2019.

SARLET, I. W.; FIGUEIREDO, M. F. Algumas considerações sobre o direito fundamental à proteção e promoção da saúde aos 20 anos da Constituição Federal de 1988. Revista dos Tribunais. São Paulo, vol. 67, jul. 2008.

SAUVÉ, M.R. Santé humaine et santé animale, même combat! Edição de 26 nov. 2019. Disponível em: https://nouvelles.umontreal.ca/article/2019/11/26/santehumaine-et-santeanimale-meme-combat/ Acesso em: 19 jun. 2020.

UNIMED. Animais de estimação podem ajudar no tratamento de doenças. Disponível em: $<$ https://www.unimedvtrp.com.br/animais-de-estimacao-podemajudar-no-tratamento-dedoencas/>. Acesso em: 30 jan. 2020.

VIEIRA, T. R.; CARDIN, V. S. G. Antrozoologia e Direito: o afeto como fundamento da família multiespécie. Revista de Biodireito e Direito dos Animais, Brasília, v. 3, n. 1, p. 127-141, 2017.

VIEIRA, T.R. A vulnerabilidade do animal abandonado, família e direito. In_Família Multiespécie: Animais de estimação e direito. Tereza Rodrigues Vieira e Camilo Henrique Silva organizadores. Brasília: Zakarewicz, 2020.

VIEIRA, T.R.; MOSSOI, A.C. Zooterapia e a contribuição dos animais para a saúde da família. In_Família Multiespécie: Animais de estimação e direito. Tereza Rodrigues Vieira e Camilo Henrique Silva organizadores. Brasília: Zakarewicz, 2020.

WISNIEWSKI, P. C. Animais de estimação como seres de direito e a (im)possibilidade da guarda nos casos de ruptura do vínculo conjugal dos guardiões. Revista interdisciplinar de ciência aplicada. Rio Grande do Sul, vol. 04, jun. 2019.

Revista de Biodireito e Direito dos Animais | e-ISSN: 2525-9695 | Encontro Virtual | v. 6 | n. 2 | p. 56 - 78 | Jul/Dez. 2020. 
WITTER, I. C.. A família contemporânea e o animal doméstico: Uma reflexão acerca do status do animal no contexto familiar e os efeitos dessa relação no Direito. Disponível em: < http://repositorio.uscs.edu.br/bitstream/123456789/1109/2/WITTER\%2C\%20I.\%20C. $\% 20 \mathrm{~A} \% 20$ fam $\%$ C3\%ADlia\%20contempor\%C3\%A2nea\%20e\%20o\%20animal\%20do m\%C3\%A9stico_2016.2.pdf>. Acesso em: 28 jan. 2020. 